This peer reviewed manuscript has been accepted for publications to the Lubrication Science. Cite this article as: M. Kalin, A. Kupec, The dominant effect of temperature on the fatigue behaviour of polymer gears, Wear, Volumes 376-377, Part B, 2017, Pages 1339-1346, ISSN 00431648, https://doi.org/10.1016/j.wear.2017.02.003.

\title{
The dominant effect of temperature on the fatigue behaviour of polymer gears
}

\author{
M. Kalin, A. Kupec \\ Laboratory for tribology and interface nanotechnology, Faculty of Mechanical Engineering, \\ University of Ljubljana, Bogišičeva 8, 1000 Ljubljana, Slovenia
}

\begin{abstract}
The testing procedures and reported tribological performance of polymer gears, which are seeing ever-increasing use by industry, still lack consistency and detail. One of the key parameters that affect a polymer's mechanical properties, interface contact conditions and, consequently, the wear and fatigue behaviour, is the temperature. Temperature is well known to have a critical influence on all polymers, much more so than on metals or other materials. However, the temperatures - even for the same load and velocity - vary greatly with testing devices, gear sizes and shapes, surrounding environment, as do the cooling and heating rates. Moreover, the temperature, either root, flank or bulk, also varies with the operating conditions, meaning that even in the same S-N curve data at different stresses we actually obtain different temperatures. This suggests that the results from different tests and even different load levels, which are not temperature controlled, cannot be directly compared due to the important influence of the temperature on the polymers. This work presents the results of POM gears tested against steel gears under well-controlled temperature conditions, providing various $\mathrm{S}-\mathrm{N}$ curves obtained at $30{ }^{\circ} \mathrm{C}, 50{ }^{\circ} \mathrm{C}$ and $70{ }^{\circ} \mathrm{C}$ that were kept constant at the gear root for three torque values $(1.0 \mathrm{Nm}, 1.2 \mathrm{Nm}$ and $1.4 \mathrm{Nm})$, and these are compared to data obtained under conditions that are typically considered to be "room temperature", which is in fact an uncontrolled temperature. The results confirm the important effect of the temperature on the fatigue life of POM gears, i.e., when kept at low temperature $\left(30^{\circ} \mathrm{C}\right)$, the fatigue life of POM gears is greatly improved.
\end{abstract}

Keywords: Polyacetal, polymer, gear, temperature, fatigue

\section{Introduction}

The use of plastic gears dates back to the 1950s, but they are nowadays gaining increasing attention due to their potential to substitute the metal gears in various applications, i.e., automotive, medical, food, to mention only a few $[1,2]$. The main advantages of plastic gears over metal ones are the ease of production with low manufacturing costs, good noise-damping properties, good tribological 
This peer reviewed manuscript has been accepted for publications to the Lubrication Science.

Cite this article as: M. Kalin, A. Kupec, The dominant effect of temperature on the fatigue behaviour of polymer gears, Wear, Volumes 376-377, Part B, 2017, Pages 1339-1346, ISSN 00431648, https://doi.org/10.1016/j.wear.2017.02.003.

properties without lubrication, as well as chemical inertness [3]. The main disadvantages that limit the use of plastic gears are their poorer mechanical properties, lower thermal conductivity and stability, i.e., lower operating temperatures, as compared to metal.

It is well known that due to their thermal properties, polymers are very sensitive to the temperature in tribological contacts. This obviously suggests frictional heating, since a relatively small increase in the temperature can make a significant and step-change deterioration in the mechanical and tribological properties [3-5]. In addition, the temperatures developed in the tribological contact can also vary significantly with the counter-face material [6-8]. The temperature is difficult to predict theoretically, because the material's mechanical properties and deformation go thorough significant modifications within the contacts, and possibly even more with the uncertainty in the real contact area $[8,9]$. Currently, the gear temperature can be predicted based on standards $[10,11]$, mostly derived from metal gear practice, for a very limited number of plastic materials. However, a comparison of the allowable endurance limits of the standards with the results obtained from the gear testing reveal that large discrepancies exist [12-14]. Accordingly, some kind of contacttemperature measurements seems to be a more pragmatic option. An infrared camera [12-16] has frequently been used to evaluate the average surface temperatures in a tribological contact.

The heat generated during the operation of polymer gears has two sources: the heat generated by frictional losses and the heat generated by hysteresis losses [17]. Surface-temperature measurements reveal an increase in the temperature with an increasing gear-pair coefficient of friction, torque (load) and speed, and that a rise in temperature causes an increase in wear and fatigue failure under high stress [13, 14, 16, 18, 19].

In order to understand polymer-gear failures, the fatigue life, the wear and the wear mechanisms have been widely studied for different polymer gears [8, 12, 13, 16, 19-21]. The most common failure modes for polymer gears are a decrease of the tooth thickness due to wear, melting due to thermal overload and tooth root/pitch fracture due to mechanical overload [8, 12, 13, 16, 19, 22]. Compositional modifications (reinforcements, internal lubricants, nanocomposites) [8, 12, 14, 16, $20,22]$, gear processing [23], gear geometry [12], counterface material [8, 12], as well the material on the driving/driven gear [19] can all influence the surface temperatures generated and thus influence the failure mechanisms, fatigue and wear rates.

Some of the most frequently used materials for polymer gears are polyacetals (POM), due to their good wear resistance combined with good strength and toughness. In particular, POM gears are well-known for their good fatigue behaviour [24], even without reinforcements, and are a common polymer gear material, especially in the mass production of polymer gears. However, a dramatic 
This peer reviewed manuscript has been accepted for publications to the Lubrication Science.

Cite this article as: M. Kalin, A. Kupec, The dominant effect of temperature on the fatigue behaviour of polymer gears, Wear, Volumes 376-377, Part B, 2017, Pages 1339-1346, ISSN 00431648, https://doi.org/10.1016/j.wear.2017.02.003.

increase in the wear rate above the critical torque has been reported $[13,14,21]$ for POM gears, which is also consistent with the results of a model-based pin-on-disc test [25] that connected this behaviour to the maximum temperature, reaching the melting point $\left(175^{\circ} \mathrm{C}\right)$ or the maximum longterm service temperature $\left(110^{\circ} \mathrm{C}\right)$.

Based on such an observed influence of the increased temperature on the POM wear performance it is reasonable to assume that the gear fatigue life can also exhibit a strong dependence on the ambient and, most importantly, the gear root temperature. Indeed, a limited number of studies have investigated polymer-gear performance at elevated temperatures [13, 22], as well at a decreased running temperature [26, 27], and revealed the influence of temperature on the wear and/or fatigue behaviour. For example, Mao et al. [13] reported a substantially reduced torque at which the transition from low to high wear occurs as a response to increased ambient temperature. The influence of a well-controlled gear-root temperature on the polymer-gear fatigue life is, however, lacking in the literature.

The aim of this study was to investigate the influence of torque and well-controlled temperature conditions on the fatigue life and wear performance of POM gears, and compare it with results obtained in typical "room-temperature" conditions where the temperature is not controlled. The influences of three torque levels and three pre-set POM gear-root temperatures, as well as the uncontrolled temperature, on fatigue life and efficiency were investigated.

\section{Experimental}

Polyoxymethylene or polyacetal (POM) gears were mated against a steel (1.2312, DIN 40CrMnMoS8-6) gear (SS). The plastic gears were injection moulded from commercially available homopolymer (Delrin 100P NC010) granules. An involute gear geometry was selected because of its common use and the specifications of the gears are collected in Table 1. Despite the fact that the hardness values of POM and SS cannot be directly compared, they are given in the table for completeness.

Table 1: Geometry and specification of running spur gears. *From manufacturer's data sheet. Driving SS gear / pinion Driven POM gear / wheel

\section{Module}

Number of teeth

Face width $(\mathrm{mm})$

1

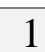


This peer reviewed manuscript has been accepted for publications to the Lubrication Science.

Cite this article as: M. Kalin, A. Kupec, The dominant effect of temperature on the fatigue behaviour of polymer gears, Wear, Volumes 376-377, Part B, 2017, Pages 1339-1346, ISSN 00431648, https://doi.org/10.1016/j.wear.2017.02.003.

Standard pressure angle $\left(^{\circ}\right)$ 20

20

Profile shift

Roughness $-\mathrm{R}_{\mathrm{a}}(\mu \mathrm{m})$

Hardness*

Melting temperature* $\left({ }^{\circ} \mathrm{C}\right)$

Thermal conductivity* (W/m.K)

0

0.60

0.36

Modulus of elasticity* (MPa)

$51 \mathrm{HRC}$

1500

33.3

210000
120 (Rockwell-R)

178

0.4

2900

The fatigue tests of spur gears were performed on a polymer-gear testing rig for small polymer gears, as shown schematically in Figure 1a. The test rig consists of a driving shaft with a servomotor that is used to control the operating speed of the driven shaft with a magnetic brake unit that provides a braking torque. Both shafts are equipped with torque cells. The driving shaft has adjustable lateral y-position that enables to adjust operating gear centre distance for gear properties, temperature and humidity variations, as well as the driven shaft has adjustable lateral x-position for ease of installation of new gears. The test rig makes it possible to study the efficiency, wear, temperature and cycles to failure of the operating gears in real time. The efficiency is calculated based on the measured input and output torques and transmission ratio, which is 1.18. With the use of an infra-red (IR) thermal camera, the real-time operating temperature can be measured and controlled using a feed-back loop, which is linked to the IR camera measurement of gear root temperature.

An Optris PI400 (Optris GmbH, Germany) thermal camera was used to measure the surface root temperature of the driven gear, as shown in Figure 1b. The area of the temperature measurement was approximately $1 \mathrm{~mm}^{2}$, which corresponds to about 100 pixels. Based on the measurements and calibration procedure, the emissivity of the driven test gear was set at a constant value of 0.92 .
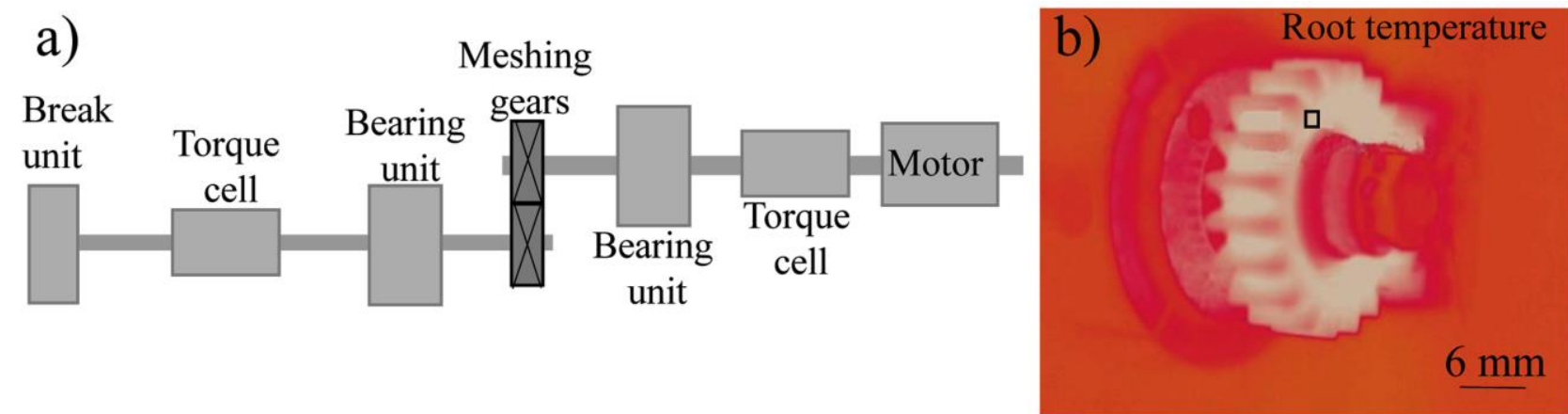
This peer reviewed manuscript has been accepted for publications to the Lubrication Science.

Cite this article as: M. Kalin, A. Kupec, The dominant effect of temperature on the fatigue

behaviour of polymer gears, Wear, Volumes 376-377, Part B, 2017, Pages 1339-1346, ISSN 0043-

1648, https://doi.org/10.1016/j.wear.2017.02.003.

\section{Figure 1: a) Schematic of polymer-gear test rig and b) a thermographic picture of the root- temperature measurements during testing.}

The measurements were conducted without any lubrication, at different torques, i.e., at 1.0, 1.2 and 1.4 Nm, which corresponded to 26.3, 30.7 and 34.8 MPa tooth-root stress (calculated according to [10]). The speed was constant at $1500 \mathrm{r} / \mathrm{min}$. The temperature in the tests was ambient, i.e., at an uncontrolled temperature, denoted as $\mathrm{NC}$-T, which was maintained at $24 \pm 2{ }^{\circ} \mathrm{C}$ during testing and $40 \pm 5 \%$ (room temperature). However, other tests were performed at a controlled gear-root temperature in an atmospheric chamber where the driving-gear-root temperature was set to $30{ }^{\circ} \mathrm{C}$, $50{ }^{\circ} \mathrm{C}$ or $70{ }^{\circ} \mathrm{C}$. The gear tests were conducted for up to $2 \times 10^{6}$ cycles or up to failure - whichever came earlier. The operating centre distance was regulated to accommodate the thermal expansion of the polymer gears. Each test was repeated at least three times.

In order to understand the influence of the load and the temperature on the gear-failure mechanisms and their causes, additional tests were performed and stopped after a selected intermediate number of cycles. Each time a new test was run up to the number of cycles, determined on the basis of previously measured fatigue-life data. For the study at room temperature the tests were stopped at 0.1, 0.3, 1 and 2 million cycles, whereas for the study at controlled temperatures, they were stopped at $0.3,0.6$ and 2 million cycles. The wear of at least four teeth on each gear was analysed using an optical microscope (Nikon, LV150).

\section{Results}

\subsection{Experiments at "room temperature", i.e., the uncontrolled temperature}

The fatigue life of the POM gears running against a steel gear as a function of torque at the uncontrolled temperature is shown in Figure 2. At a torque of $1.4 \mathrm{Nm}$ the POM gears failed after $526 \times 10^{3} \pm 45 \times 10^{3}$ cycles. A decrease in the torque to a value of $1.2 \mathrm{Nm}$ resulted in an improved fatigue life of the POM gears, as revealed by a more than $2 \times$ increase in the number of cycles to failure, i.e., $1283 \times 10^{3} \pm 141 \times 10^{3}$. When running at $1 \mathrm{Nm}$, the polymer gears did not fail until $2 \times$ $10^{6}$ cycles, when the test was stopped. 
This peer reviewed manuscript has been accepted for publications to the Lubrication Science. Cite this article as: M. Kalin, A. Kupec, The dominant effect of temperature on the fatigue behaviour of polymer gears, Wear, Volumes 376-377, Part B, 2017, Pages 1339-1346, ISSN 00431648, https://doi.org/10.1016/j.wear.2017.02.003.

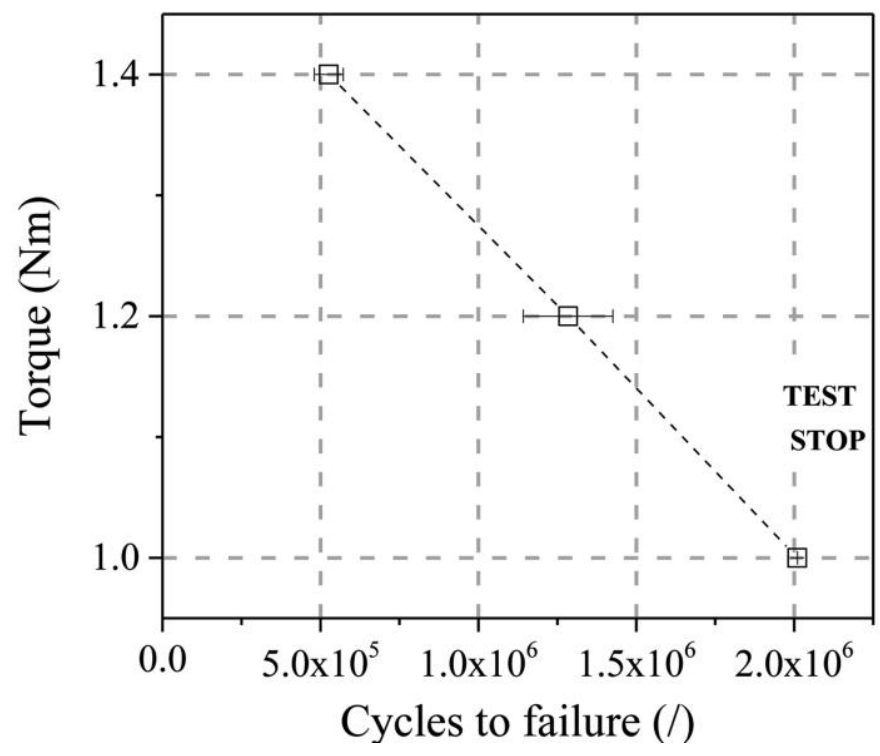

Figure 2: S-N curves of polymer (POM) gears running against steel (SS) gears as a function of torque, at room temperature, i.e., non-controlled temperature.

Throughout the tests, the root temperature of the driven polymer gears was followed as shown in Figure $1 \mathrm{~b}$ and the results are collected in Figure 3. Regardless of the torque, a steep increase in temperature in the very early stage of running (less than $\sim 50 \times 10^{3}$ cycles) is followed by a more modest, but obvious, increase in the temperatures throughout the whole measurement, see Figure 3b. This increase in the temperature during the test was 2,4 and $8{ }^{\circ} \mathrm{C}$ at $1.0,1.2$ and $1.4 \mathrm{Nm}$ of torque. Just before failure at 1.2 and $1.4 \mathrm{Nm}$, the temperature increased abruptly, and finally the gear tooth broke. The temperature therefore never stabilizes, but continues to increase, even up to 2 million cycles.

The average root temperature values for "normal" operating, before a steep temperature increase and failure, were 46,58 and $64{ }^{\circ} \mathrm{C}$ at $1.0,1.2$ and $1.4 \mathrm{Nm}$, respectively, which is about 20 to $40{ }^{\circ} \mathrm{C}$ higher than considered as room temperature $\left(24^{\circ} \mathrm{C}\right)$. Accordingly, depending on the torque and the test duration, the root temperature can be anywhere within the range $20-70{ }^{\circ} \mathrm{C}$. 
This peer reviewed manuscript has been accepted for publications to the Lubrication Science. Cite this article as: M. Kalin, A. Kupec, The dominant effect of temperature on the fatigue behaviour of polymer gears, Wear, Volumes 376-377, Part B, 2017, Pages 1339-1346, ISSN 00431648, https://doi.org/10.1016/j.wear.2017.02.003.
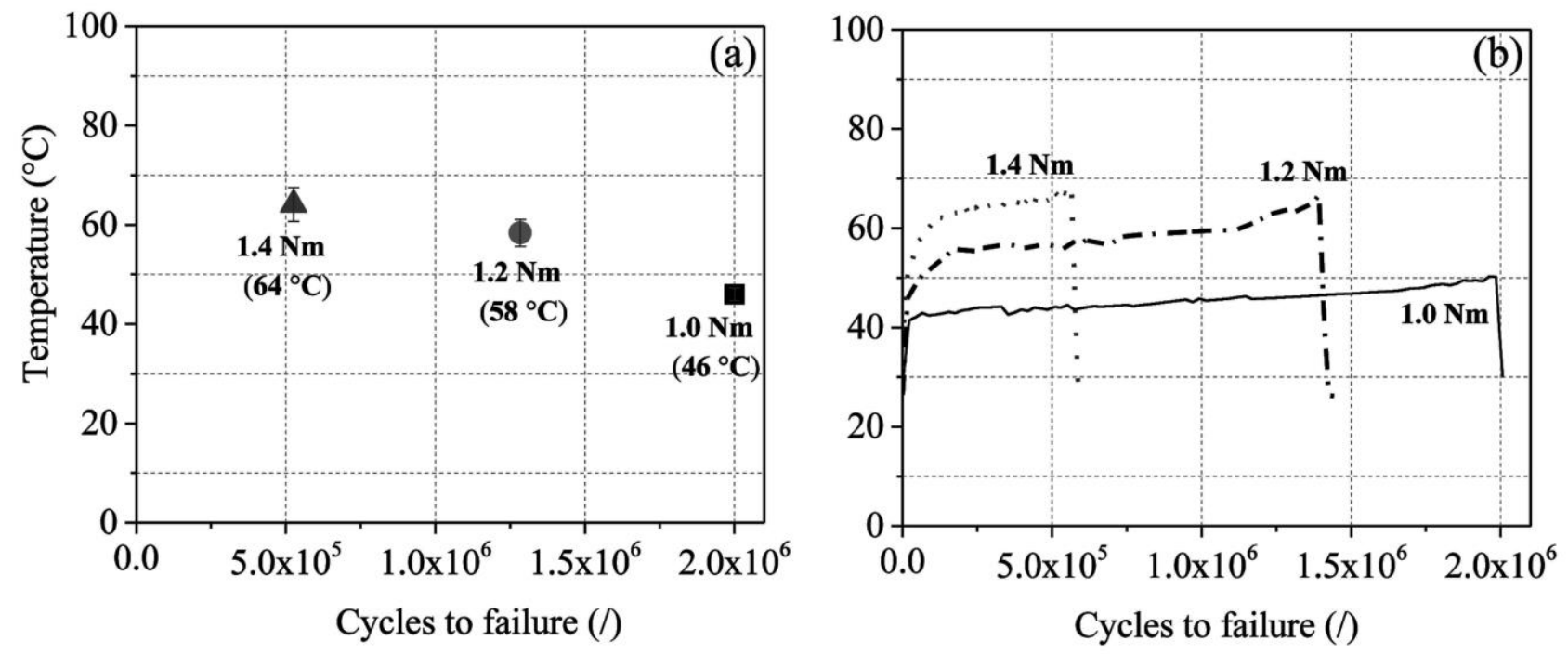

Figure 3: (a) Average root-temperature values of multiple measurements as a function of torque at room temperature, i.e., uncontrolled temperature and (b) evolution of the temperature in a single measurement.

The evolution of the efficiency and its torque-dependent average values are collected in Figure 4. The initial increase within the first $10 \times 10^{3}$ cycles is followed by relatively stable values of the efficiency in the measured torque range. The average efficiency at $1.4 \mathrm{Nm}$ is $90 \pm 0.57 \%$, and it increases to $93 \pm 1.33 \%$ and to $96 \pm 0.98 \%$ as the torque is decreased to $1.2 \mathrm{Nm}$ and $1 \mathrm{Nm}$, respectively.

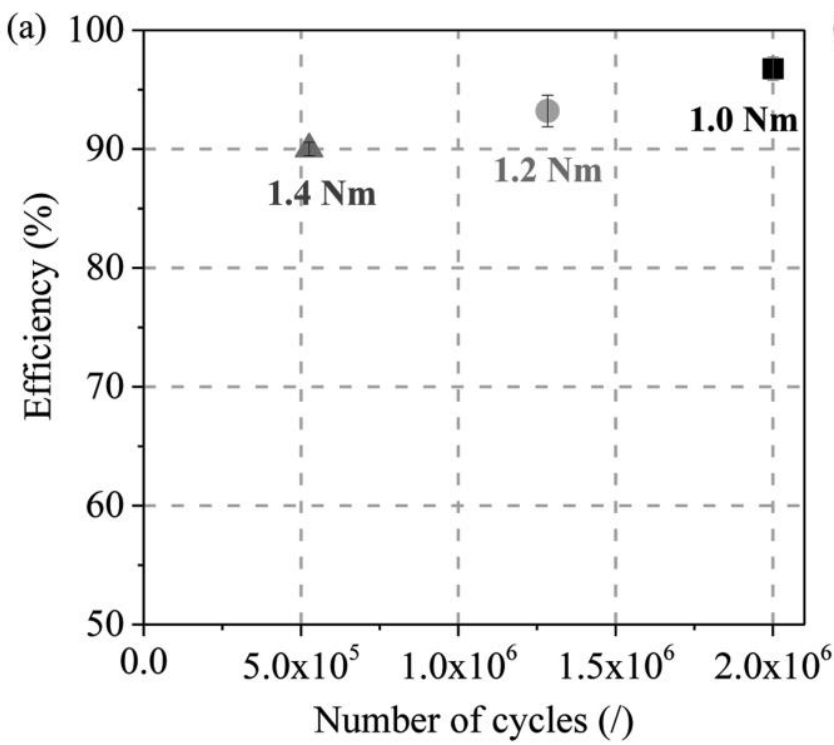

(b)

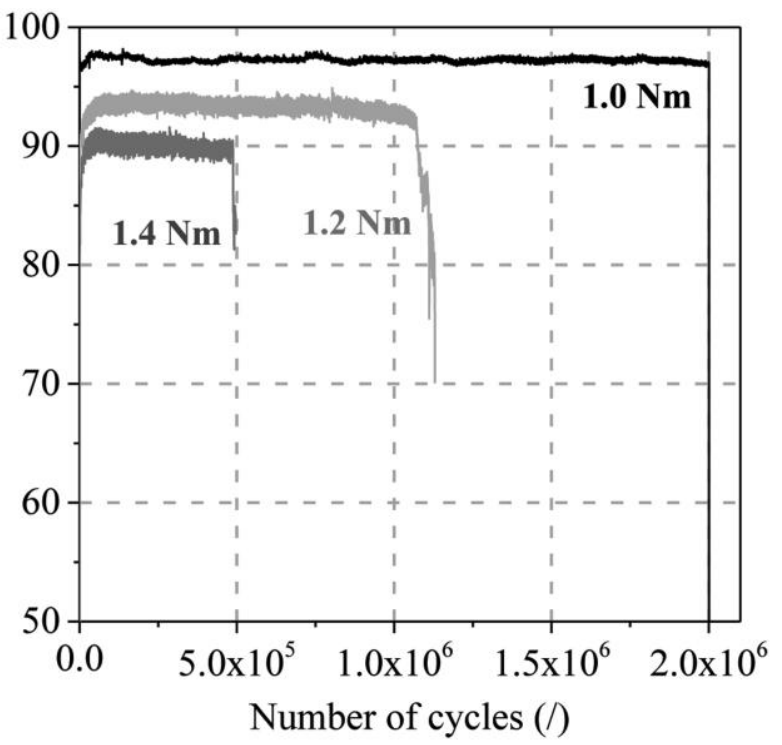


This peer reviewed manuscript has been accepted for publications to the Lubrication Science. Cite this article as: M. Kalin, A. Kupec, The dominant effect of temperature on the fatigue behaviour of polymer gears, Wear, Volumes 376-377, Part B, 2017, Pages 1339-1346, ISSN 00431648, https://doi.org/10.1016/j.wear.2017.02.003.

Figure 4: (a) Average efficiency values of multiple measurements as a function of torque at room temperature, i.e., the uncontrolled temperature and (b) the evolution of efficiency in a single measurement.

In order to study the influence of torque on the gear-failure mechanism, additional tests were performed and terminated after an intermediate number of cycles. Figure 5 collects optical images of the representative worn teeth profiles. The dotted lines denote the initial shape of a new, unworn tooth.

After running a gear pair at $1 \mathrm{Nm}$ torque for $100 \times 10^{3}$ cycles, the POM gear retains its initial shape. After $300 \times 10^{3}$ cycles, very minor wear on the lower part of the tooth can be observed. As the number of cycles increases to $1000 \times 10^{3}$, the tooth thickness decreased slightly, indicating some mild wear. However, even though the gear did not fail, after running for $2000 \times 10^{3}$ cycles the wear of the teeth is obvious and spread over the whole contact zone. In addition, after $2000 \times 10^{3}$ cycles, the tooth wear is accompanied by a barely noticeable tooth tilting.

At $1.2 \mathrm{Nm}$ the changes in the tooth profile are small after $100 \times 10^{3}$ cycles, while a larger number of cycles $\left(300\right.$ and $1000 \times 10^{3}$ ) results in a continuously increasing wear and also notable tilting of the tooth. The extent of both the wear and the plastic deformation in terms of the tilt are notably higher compared to $1.0 \mathrm{Nm}$. After $1280 \times 10^{3}$ cycles, the POM gear failed. It is clear that between 1 million cycles and 1.28 million cycles, i.e., in a relatively short period, a dramatic increase in the wear and deformation occurred and led to catastrophic failure, via the tooth-root fracture.

At $1.4 \mathrm{Nm}$ an observable wear, as well as slightly tilted teeth, already after just $100 \times 10^{3}$ cycles was observed, in agreement with an increase in the load. After $300 \times 10^{3}$ cycles, the area of worn material is already spread across the whole contact zone, which is accompanied by a severe tooth tilting. At $520 \times 10^{3}$ cycles the gear failed via the tooth-root fracture. Similar to $1.2 \mathrm{Nm}$, a sharp transition in wear damage occurred between 300 and $530 \times 10^{3}$ cycles. 
This peer reviewed manuscript has been accepted for publications to the Lubrication Science.

Cite this article as: M. Kalin, A. Kupec, The dominant effect of temperature on the fatigue

behaviour of polymer gears, Wear, Volumes 376-377, Part B, 2017, Pages 1339-1346, ISSN 00431648, https://doi.org/10.1016/j.wear.2017.02.003.

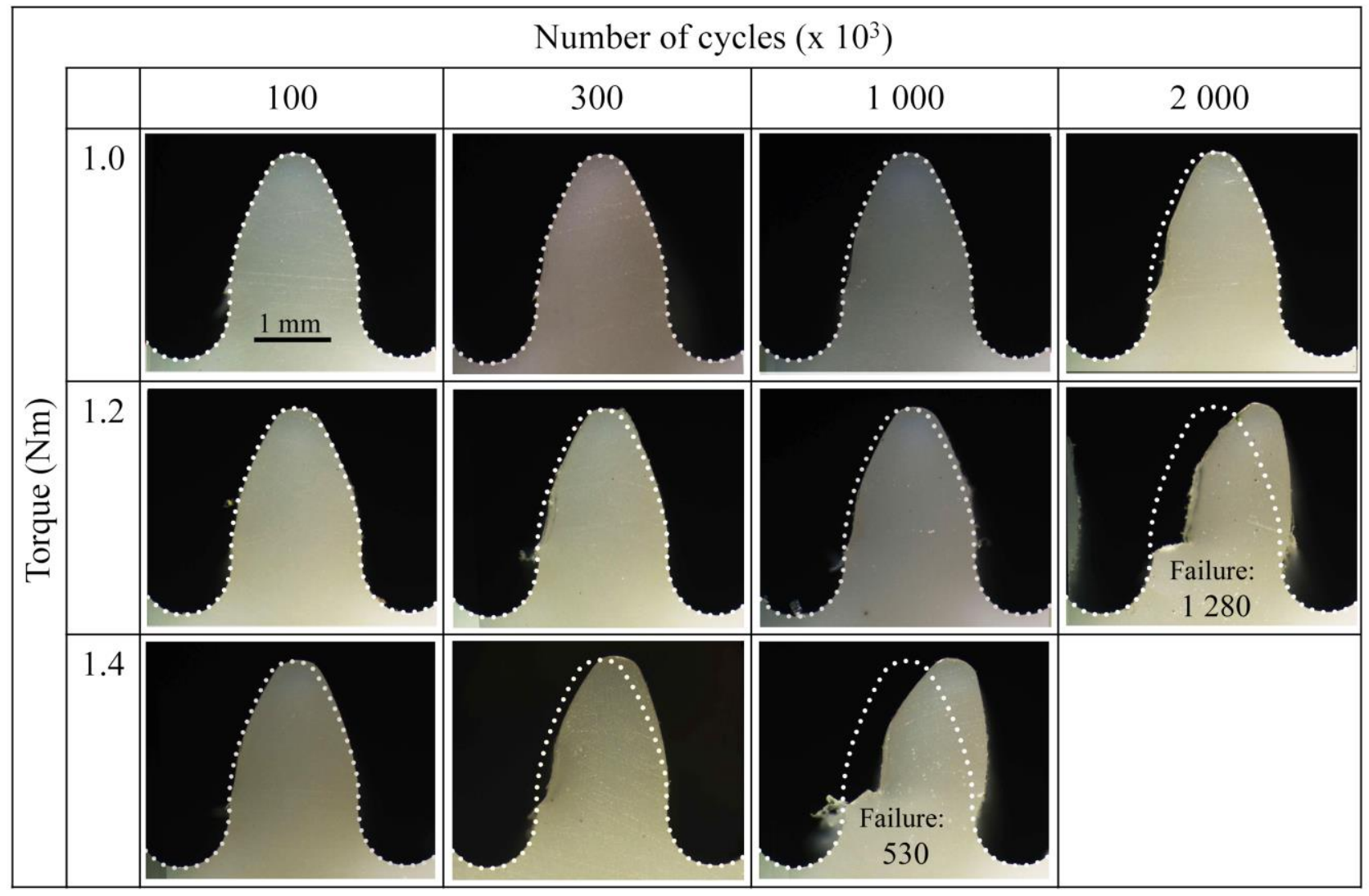

Figure 5: Teeth wear and deformation with increasing number of cycles at room temperature, i.e., uncontrolled temperature. Note: the scale bar is the same for all figures.

\subsection{Experiments at well-controlled temperatures}

In order to investigate the influence of the actual gear-root temperature on the fatigue life and teeth degradation failure mode, the POM/SS gear pairs were meshed at controlled temperatures, i.e., at 30 ${ }^{\circ} \mathrm{C}, 50{ }^{\circ} \mathrm{C}$ and $70{ }^{\circ} \mathrm{C}$. Figure 6 shows the gear-root temperatures of the POM gears, measured throughout the whole measurement at different torques. Regardless of the temperature and torque conditions selected, the selected root temperature was kept almost completely constant, with the deviations not exceeding $\pm 0.5^{\circ} \mathrm{C}$. 
This peer reviewed manuscript has been accepted for publications to the Lubrication Science.

Cite this article as: M. Kalin, A. Kupec, The dominant effect of temperature on the fatigue behaviour of polymer gears, Wear, Volumes 376-377, Part B, 2017, Pages 1339-1346, ISSN 00431648, https://doi.org/10.1016/j.wear.2017.02.003.
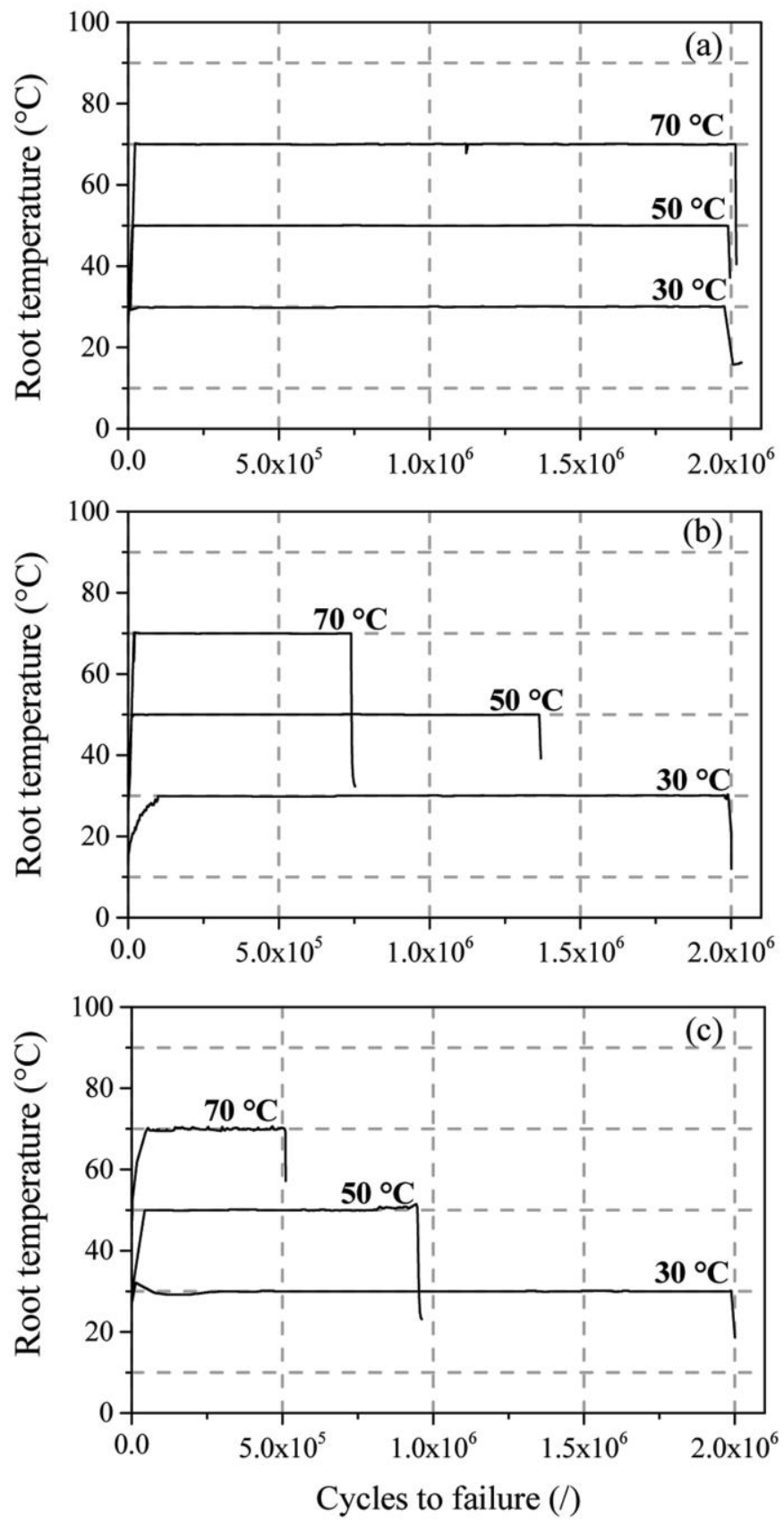

Figure 6: Root temperatures of POM gear while running against steel gear at (a) $1.0 \mathrm{Nm}$, (b) $1.2 \mathrm{Nm}$ and (c) $1.4 \mathrm{Nm}$.

The S-N curves, obtained at the controlled gear-root temperatures of $30{ }^{\circ} \mathrm{C}, 50{ }^{\circ} \mathrm{C}$ and $70{ }^{\circ} \mathrm{C}$, are collected in Figure 7. The fatigue lives of the gear pairs meshed at uncontrolled temperature, adapted from Figure 2, are added for comparison.

At $30{ }^{\circ} \mathrm{C}$ all the POM gears reached $2000 \times 10^{3}$ cycles without failure and the tests were stopped. At $50{ }^{\circ} \mathrm{C}$, the number of cycles decreased as the torque was increased, still surviving 2 million cycles at $1.0 \mathrm{Nm}$. However, at $1.2 \mathrm{Nm}$, the gear failed at 1.6 and at $1.4 \mathrm{Nm}$ after 0.9 million cycles. 
This peer reviewed manuscript has been accepted for publications to the Lubrication Science. Cite this article as: M. Kalin, A. Kupec, The dominant effect of temperature on the fatigue behaviour of polymer gears, Wear, Volumes 376-377, Part B, 2017, Pages 1339-1346, ISSN 00431648, https://doi.org/10.1016/j.wear.2017.02.003.

When the temperature is increased to $70{ }^{\circ} \mathrm{C}$, the same as for the lower temperatures, the gears could run for up to 2 million cycles at $1.0 \mathrm{Nm}$, but their life was significantly reduced at $1.2 \mathrm{Nm}$, to only 0.8 , and at $1.4 \mathrm{Nm}$ even to 0.4 , million cycles.

These result show the dramatic effect of the gear-root temperature, which is at $1.4 \mathrm{Nm}$ and $70{ }^{\circ} \mathrm{C}$ decreased by more than four times and at $50{ }^{\circ} \mathrm{C}$ by more than two times, compared to $30{ }^{\circ} \mathrm{C}$. Similarly, at $1.2 \mathrm{Nm}$ and $70{ }^{\circ} \mathrm{C}$ the decrease compared to $30{ }^{\circ} \mathrm{C}$ is more than two times and at $50{ }^{\circ} \mathrm{C}$ by $20 \%$.

It should be noted that the data for the uncontrolled temperatures that were measured at 46,58 and $64{ }^{\circ} \mathrm{C}$ correspond extremely well to the results obtained at the controlled temperatures, i.e., just in between these curves. This indicates a strong, but also a very sensitive, effect of the actual root temperature on the fatigue life.

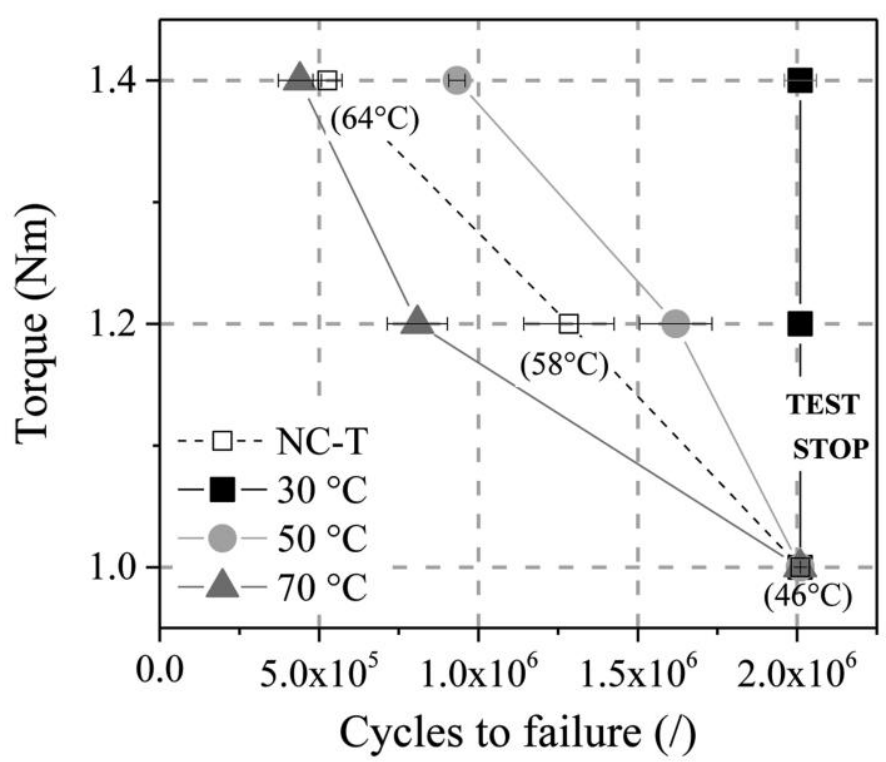

Figure 7: S-N curves at controlled root temperatures. The curve obtained without temperature control (NC-T) is adapted from Figure 2 for comparison.

The average values and evolution of the efficiency are collected in Figures 8 and 9, respectively. In all cases, the efficiency is above $90 \%$ in the stable range, reaching average values of $97 \pm 1.91 \%$ at $1.0 \mathrm{Nm}, 94 \pm 0.42$ at $1.2 \mathrm{Nm}$ and $92 \pm 0.85$ at $1.4 \mathrm{Nm}$. Similar to the tests conducted at the uncontrolled temperature (Figure 4a), the efficiencies decrease with the increasing torque. However, the deviations of the efficiencies with torque become more pronounced as the root temperature is 
This peer reviewed manuscript has been accepted for publications to the Lubrication Science. Cite this article as: M. Kalin, A. Kupec, The dominant effect of temperature on the fatigue behaviour of polymer gears, Wear, Volumes 376-377, Part B, 2017, Pages 1339-1346, ISSN 00431648, https://doi.org/10.1016/j.wear.2017.02.003.

increased. Namely, the efficiency decreases by 3,5 and $9 \%$ at $30{ }^{\circ} \mathrm{C}, 50{ }^{\circ} \mathrm{C}$ and $70{ }^{\circ} \mathrm{C}$, respectively, as the torque is increased from $1 \mathrm{Nm}$ to $1.4 \mathrm{Nm}$.

Regardless of the torque or the temperature applied during the test, the initial increase in efficiency is followed by relatively stable values in the measured torque range. In the case of gear failure prior to $2000 \times 10^{3}$ cycles, sharp deviations in the efficiency in the last cycles before failure could be connected to the severe damage taking place on the individual teeth.

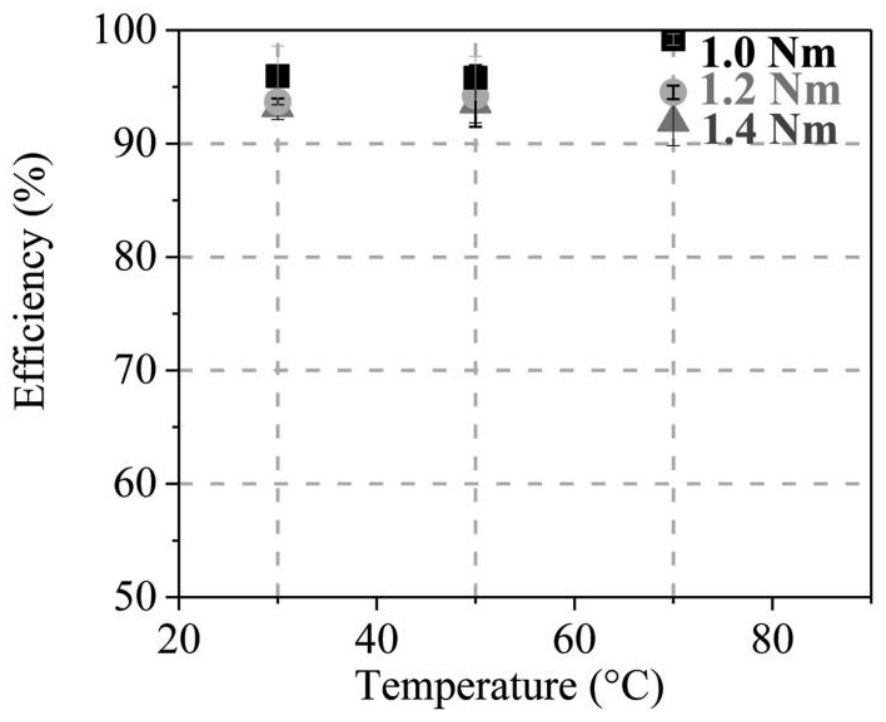

Figure 8: Average gear-pair efficiency at controlled root temperatures. 
This peer reviewed manuscript has been accepted for publications to the Lubrication Science. Cite this article as: M. Kalin, A. Kupec, The dominant effect of temperature on the fatigue behaviour of polymer gears, Wear, Volumes 376-377, Part B, 2017, Pages 1339-1346, ISSN 00431648, https://doi.org/10.1016/j.wear.2017.02.003.
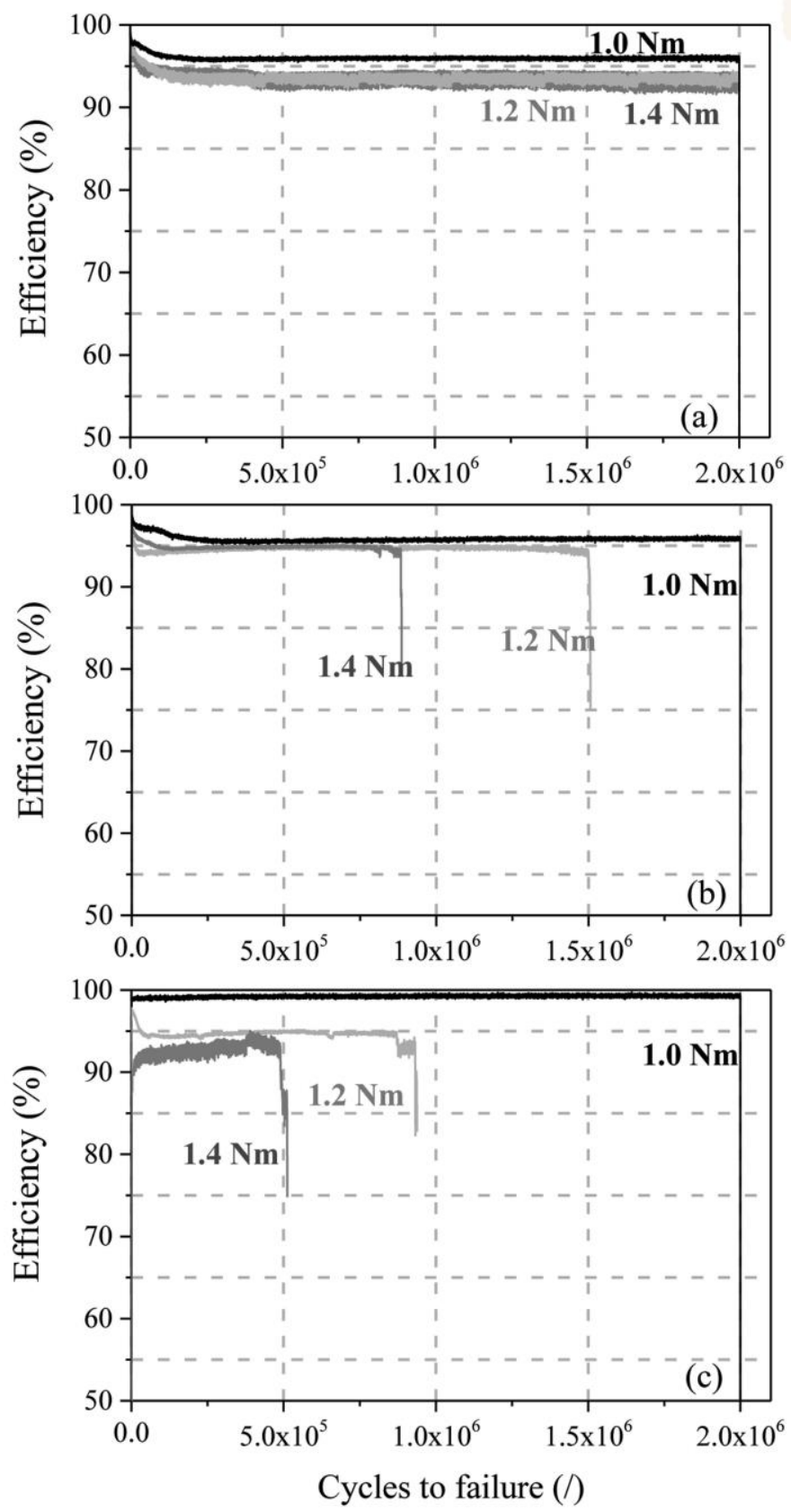

Figure 9: Evolution of gear efficiency as a function of torque (1.0 Nm, 1.2 $\mathrm{Nm}$ and $1.4 \mathrm{Nm})$ at controlled gear-root temperatures (a) $30{ }^{\circ} \mathrm{C}$, (b) $50{ }^{\circ} \mathrm{C}$ and (c) $70{ }^{\circ} \mathrm{C}$.

In order to study the influence of the gear-root temperature on the failure mechanism, in particular at the highest torque, where the changes are the most severe, additional tests at selected temperatures were performed up to 300,600 and $2000 \times 10^{3}$ cycles and the results are collected in Figure 10. 
This peer reviewed manuscript has been accepted for publications to the Lubrication Science.

Cite this article as: M. Kalin, A. Kupec, The dominant effect of temperature on the fatigue

behaviour of polymer gears, Wear, Volumes 376-377, Part B, 2017, Pages 1339-1346, ISSN 0043-

1648, https://doi.org/10.1016/j.wear.2017.02.003.

Running for $300 \times 10^{3}$ cycles at $30{ }^{\circ} \mathrm{C}$ resulted in a minor decrease in the tooth thickness and a barely noticeable tilt of the teeth. As the number of stress cycles increases to $600 \times 10^{3}$, wear is increased and extended across a greater length of the tooth profile. After $2000 \times 10^{3}$ cycles a severe wear over the whole contact zone can be observed, while the tooth tilting remains similar to that after $300 \times 10^{3}$ cycles. At $50{ }^{\circ} \mathrm{C}$, the tooth profile is similar to that at $30{ }^{\circ} \mathrm{C}$ after a small number of cycles (i.e., $300 \times 10^{3}$ ). However, with the increasing number of cycles, the influence of temperature becomes more pronounced, as revealed by the noticeable wear over the contact zone and tooth tilt on the tooth profile after $600 \times 10^{3}$, and resulting in a gear failure after $930 \times 10^{3}$ cycles. Moreover, a further increase in the gear-root temperature to $70{ }^{\circ} \mathrm{C}$ resulted in a major wear and tilt already after $300 \times 10^{3}$ cycles and in the worst case to failure after as few as $510 \times 10^{3}$ cycles, indicating the dramatic effect of temperature, as indeed consistently measured in a number of experiments under well-controlled conditions.

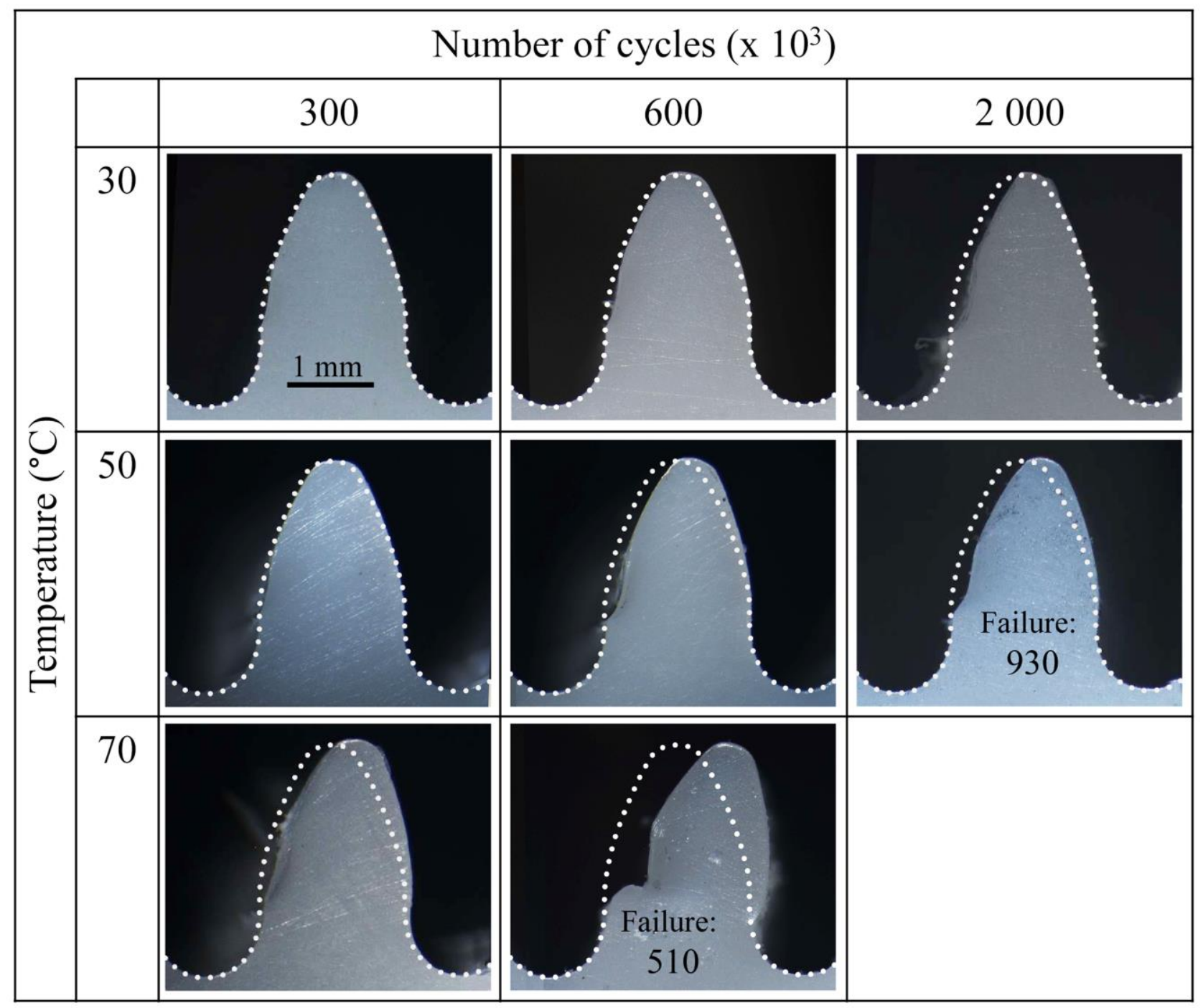


This peer reviewed manuscript has been accepted for publications to the Lubrication Science.

Cite this article as: M. Kalin, A. Kupec, The dominant effect of temperature on the fatigue

behaviour of polymer gears, Wear, Volumes 376-377, Part B, 2017, Pages 1339-1346, ISSN 0043-

1648, https://doi.org/10.1016/j.wear.2017.02.003.

Figure 10: Optical images of the worn teeth profiles with an increasing number of cycles at 1.4 $\mathrm{Nm}$ and controlled temperatures (a) $30{ }^{\circ} \mathrm{C}$, (b) $50{ }^{\circ} \mathrm{C}$ and (c) $70{ }^{\circ} \mathrm{C}$. Dotted lines correspond to initial shape of new, unworn teeth. Note: the scale bar is the same for all figures.

\section{Discussion}

This study shows that temperature has tremendous importance for the fatigue performance of polymer gears (Figure 7). When the transmitted torque/load is varied, this clearly affects the fatigue life, which is represented by a typical S-N curve. However, torque variation also changes the generated temperature due to the different friction and hysteresis deformation losses. However, as shown in this work, the temperature itself - at the same load/torque - can change the fatigue life dramatically. In our study, this was up to four times at $70{ }^{\circ} \mathrm{C}$ and up to two times at $50{ }^{\circ} \mathrm{C}$, as compared to $30{ }^{\circ} \mathrm{C}$.

Furthermore, from a comparison of Figure 5 and Figure 10, it becomes clear that when the temperature is kept low, at $30{ }^{\circ} \mathrm{C}$, there is no tooth tilting on the POM gears after running at $1.4 \mathrm{Nm}$ for $300 \times 10^{3}$ and $600 \times 10^{3}$ cycles, while at uncontrolled or high temperature $\left(50{ }^{\circ} \mathrm{C}, 70{ }^{\circ} \mathrm{C}\right)$, tooth tilting is obvious under these conditions.

Accordingly, the S-N curve is a direct consequence of both the torque/load and temperature, and so the temperature cannot be left uncontrolled for polymer gears. It is well known that temperature has a strong effect on polymer performance $[2,13,14,17]$, which is in a typical gear-operating range much more significant than for steel or other metals.

We also show that in the tests that are run at conditions typically referred to as "room temperature", the actual gear-root temperatures are actually much higher. In our case, at a torque of $1.4 \mathrm{Nm}$ that corresponds to $34.8 \mathrm{MPa}$ of equivalent root stress, this temperature was almost $40{ }^{\circ} \mathrm{C}$ above room temperature, while at $1.2 \mathrm{Nm}(30.7 \mathrm{MPa})$, the temperature was $34{ }^{\circ} \mathrm{C}$ higher. This is clearly an extremely relevant temperature increase for polymer materials that cannot be neglected.

Another interesting observation is that in uncontrolled temperature conditions, the polymer gear temperature never stabilised during 2 million cycles, but continued to increase. So, there was an accumulation of heat that cannot be removed from the gears via natural cooling, and this increase in root temperature depends on the torque. The increase was from 2 to $8{ }^{\circ} \mathrm{C}$ at the lowest and highest torques, respectively. This further shows that even with the same test, the temperature is not 
This peer reviewed manuscript has been accepted for publications to the Lubrication Science.

Cite this article as: M. Kalin, A. Kupec, The dominant effect of temperature on the fatigue behaviour of polymer gears, Wear, Volumes 376-377, Part B, 2017, Pages 1339-1346, ISSN 00431648, https://doi.org/10.1016/j.wear.2017.02.003.

constant, but depends on the gear geometry, counter-body and environmental (cooling) conditions. Nevertheless, this increase makes the test conditions even more unclear and undefined, and furthermore, calls for temperature control in polymer-gear testing.

Moreover, it was also observed that the temperature affects the efficiency. When the gears run under an uncontrolled root temperature, the average efficiency decreased by $6 \%$ as the torque increased from 1.0 to $1.4 \mathrm{Nm}$. The decrease in the efficiency with torque becomes more pronounced at elevated temperatures, i.e., by $9 \%$ at $70{ }^{\circ} \mathrm{C}$. Moreover, since under uncontrolled conditions the temperature changes during a single test, the efficiency also decreased throughout the measurement. However, the efficiency change during the tests is not only due to the temperature, but also due to a change in the coefficient of friction, gear-teeth thinning, gear-teeth deformation and so an overall change in meshing conditions.

Figure 5 shows how the gear-teeth profiles change with the testing cycles, depending on the load, and so the temperature that simultaneously affect the conditions, if it is not controlled. In such a degradation situation, the coefficient of friction changes due to wear and variations in surface conditions. As a consequence of the wear, gear thinning is also observed in the range of up to $10 \%$, which is as much as $160 \mu \mathrm{m}$. This certainly changes the running conditions, and so the fatigue life, and moreover facilitates the elastic deformation of teeth during meshing, which should not be neglected. During severe thinning, the tooth strength is also reduced, which further accelerates the teeth breakage. Accordingly, not only fatigue properties, but also wear is of relevant importance to the fatigue life, itself. Finally, the results also show a significant permanent deformation of the gear teeth that increases with the number of cycles in the form of teeth tilting. Permanent deformation has a similar negative influence on running as on the gear thinning, obviously changing the designed meshing and running conditions.

To summarise, the gear temperature changes with the change in the load, so cannot be considered constant, if it is not controlled. In such conditions the temperature changes within the same S-N curve, and even within the same experiment. Since a higher temperature, at the same load, increases deformation and wear, reduces efficiency and fatigue life, well-controlled and constant geartemperature conditions seem to be a pre-condition for a reliable, repeatable, condition-defined and controlled fatigue life testing of polymer gears.

\section{Conclusions}

The influence of load in the range of 26.3 to $34.8 \mathrm{MPa}$ of tooth root stress and temperature, i.e., uncontrolled "room temperature" or controlled in the range from $30{ }^{\circ} \mathrm{C}$ to $70{ }^{\circ} \mathrm{C}$ on the fatigue life 
This peer reviewed manuscript has been accepted for publications to the Lubrication Science.

Cite this article as: M. Kalin, A. Kupec, The dominant effect of temperature on the fatigue behaviour of polymer gears, Wear, Volumes 376-377, Part B, 2017, Pages 1339-1346, ISSN 00431648, https://doi.org/10.1016/j.wear.2017.02.003.

and damage of polymer (POM) gears in contact with steel gears was investigated and compared. Overall, this study shows that gear-temperature control cannot be neglected in the wear and fatigue testing of polymer gears. The study revealed several specific conclusions:

- A polymer-gear testing rig enables the study of the tribological properties of polymer gears under well-controlled gear temperature conditions; for very good discriminatory load conditions.

- If root temperature is not controlled, the tests performed at "room temperature" run at significantly higher temperatures, $20-40{ }^{\circ} \mathrm{C}$, depending on the torque in this study. Moreover, the temperature increases even within the same test (up to $8{ }^{\circ} \mathrm{C}$ in this work) if the cooling ability is not sufficient.

- The temperature - at the same load/torque - changes the fatigue life dramatically: up to four times at $70{ }^{\circ} \mathrm{C}$ and up to two times at $50{ }^{\circ} \mathrm{C}$, as compared to $30{ }^{\circ} \mathrm{C}$. The fatigue life is thus a direct consequence of both the torque/load and temperature, and so the temperature cannot be left uncontrolled in polymer-gears fatigue studies.

- The temperature increase also decreases the efficiency (90-97\%) by up to $9 \%$ in this work for the highest load (34.8 MPa root stress at $1.4 \mathrm{Nm}$ ) at $70^{\circ} \mathrm{C}$. A higher load also directly, or indirectly, decreases the efficiency.

- Pre-set load and temperatures affect the deformation (tooth tilting), wear and geometrical properties (tooth shape, tolerances), and so the coefficient of friction, which in turn influences the temperature and importantly changes the meshing conditions and so the results.

\section{Acknowledgements}

The authors would like to thank European Social Fund for its partial financial support and to Gleason Plastic Gears for providing us the testing gears.

\section{References}

[1] B.J. Briscoe, S.K. Sinha, Chapter 1 - Tribological applications of polymers and their composites: Past, present and future prospects, in: F. Klaus, K.S. Alois (Eds.) Tribology and interface engineering series, Elsevier, 2008, pp. 1-14.

[2] A. Abdelbary, Wear ofpolymers and composites, Elsevier, Oxford, 2014.

[3] G.W. Stachowiak, A.W. Batchelor, 16 - Wear of non-metallic materials, Engineering tribology (Third edition), Butterworth-Heinemann, Burlington, 2006, pp. 651-704.

[4] N.K. Myshkin, S.S. Pesetskii, A.Y. Grigoriev, Polymer tribology: current state and applications, Tribology in Industry, 37 (2015) 284-290. 
This peer reviewed manuscript has been accepted for publications to the Lubrication Science.

Cite this article as: M. Kalin, A. Kupec, The dominant effect of temperature on the fatigue

behaviour of polymer gears, Wear, Volumes 376-377, Part B, 2017, Pages 1339-1346, ISSN 00431648, https://doi.org/10.1016/j.wear.2017.02.003.

[5] S.K. Sinha, B.J. Briscoe, Polymer tribology, Imperial College Press, London, 2009.

[6] A. Pogačnik, A. Kupec, M. Kalin, Tribological properties of polyamide (PA6) in self-mated contacts and against steel as a stationary and moving body, submitted to Wear.

[7] M. Watanabe, M. Karasawa, K. Matsubara, The frictional properties of nylon, Wear, 12 (1968) 185-191.

[8] K.D. Dearn, T.J. Hoskins, D.G. Petrov, S.C. Reynolds, R. Banks, Applications of dry film lubricants for polymer gears, Wear, 298-299 (2013) 99-108.

[9] A. Pogačnik, T. Požar, M. Kalin, J. Možina, A homodyne quadrature laser interferometer for micro-asperity deformation analysis, Sensors, 13 (2013) 703.

[10] V. 2736:, Blatt 2. Termoplastische zahnraeder stirnradgetriebe. Tragfaehighskeit-berrechnung. VDI Richtlinien, VDI-Verlag GmbH, Duesseldorf, 2014.

[11] B. 6168, Specification for non-metallic spur gears., British Standard Institution, London, 1987.

[12] A. Pogačnik, J. Tavčar, An accelerated multilevel test and design procedure for polymer gears, Materials \& Design (1980-2015), 65 (2015) 961-973.

[13] K. Mao, A new approach for polymer composite gear design, Wear, 262 (2007) 432-441.

[14] C.J. Hooke, K. Mao, D. Walton, A.R. Breeds, S.N. Kukureka, Measurement and prediction of the surface temperature in polymer gears and its relationship to gear wear, Journal of Tribology, 115 (1993) 119-124.

[15] E. Letzelter, M. Guingand, J.-P.d. Vaujany, P. Schlosser, A new experimental approach for measuring thermal behaviour in the case of nylon 6/6 cylindrical gears, Polym. Test., 29 (2010) 1041-1051.

[16] S. Senthilvelan, R. Gnanamoorthy, Wear characteristics of injection-moulded unfilled and glass-filled nylon 6 spur gears, Proceedings of the Institution of Mechanical Engineers, Part J: Journal of Engineering Tribology, 218 (2004) 495-502.

[17] D. Koffi, R. Gauvin, H. Yelle, Heat generation in thermoplastic spur gears Journal of Mechanisms, Transmissions, and Automation in Design, 107 (1985) 31-37.

[18] K. Mao, A numerical method for polymer composite gear flash temperature prediction, Wear, 262 (2007) 1321-1329.

[19] A.R. Breeds, S.N. Kukureka, K. Mao, D. Walton, C.J. Hooke, Wear behaviour of acetal gear pairs, Wear, 166 (1993) 85-91.

[20] M. Kurokawa, Y. Uchiyama, T. Iwai, S. Nagai, Performance of plastic gear made of carbon fiber reinforced polyamide 12, Wear, 254 (2003) 468-473.

[21] S.N. Kukureka, Y.K. Chen, C.J. Hooke, P. Liao, The wear mechanisms of acetal in unlubricated rolling-sliding contact, Wear, 185 (1995) 1-8.

[22] M. Kurokawa, Y. Uchiyama, S. Nagai, Performance of plastic gear made of carbon fiber reinforced poly-ether-ether-ketone: Part 2, Tribology International, 33 (2000) 715-721.

[23] D. Drummer, B. Gierl, Possibilities and potential of plastics in gear applications, International Conference on Gears 2015, Munich, Germany, 2015.

[24] C.A. Harper, Handbook of plastics technologies: The complete guide to properties and performance, McGraw-Hill, New York, 2006.

[25] J.K. Lancaster, Estimation of the limiting PV relationships for thermoplastic bearing materials, Tribology, 4 (1971) 82-86.

[26] C.H. Kim, Durability improvement method for plastic spur gears, Tribology International, 39 (2006) 1454-1461.

[27] H. Düzcükoğlu, Study on development of polyamide gears for improvement of load-carrying capacity, Tribology International, 42 (2009) 1146-1153. 
This peer reviewed manuscript has been accepted for publications to the Lubrication Science. Cite this article as: M. Kalin, A. Kupec, The dominant effect of temperature on the fatigue behaviour of polymer gears, Wear, Volumes 376-377, Part B, 2017, Pages 1339-1346, ISSN 00431648, https://doi.org/10.1016/j.wear.2017.02.003. 